\title{
Construir el hueco para habitar su borrado: Unas notas sobre la poesía de Josep M. Rodríguez
}

\begin{abstract}
En este artículo se estudia la poesía de Josep M. Rodríguez como indagación en el misterio de lo real, pero también como un modo de ser en la realidad, que condiciona un yo desenfocado, que trata de afirmarse negándose como acto de existencia pero también como acto de lenguaje. La escritura poética no es, entonces, el modo de plasmar la subjetividad, sino la forma de constatar su ausencia; no es un modo de ser, sino de borrarse. Escribir poesía es una invitación a la comprensión de una realidad fragmentaria.
\end{abstract}

Keywords: Josep M. Rodríguez, poesía española actual, posmodernidad, fragmentarismo

En «Autorretrato», un poema incluido en Raíz (2008), escribe Josep M. Rodríguez (Súria, Barcelona, 1976) unos versos que pueden ser imagen de lo que su escritura poética pretende: «Suelo venir aquí en los días de niebla / para ver cómo el puente / no alcanza la otra orilla»' En cierto modo, en esa imagen aparece condensada su concepción de la poesía: un puente tendido hacia un misterio que nunca se resuelve; una niebla que nunca desaparece, pero que nos induce a pensar que hay un más allá de lo que las palabras alcanzan a decir. Ese misterio es la realidad, que nunca se desvela, pues solo se nos muestra en su superficialidad, en su corteza («y este poema / no es más que la corteza de lo que está pasando», dice en «La charca»), en su oscuridad («pintar la oscuridad desde la oscuridad», leemos en «Principio y fin»3); se nos muestra ocultándose, y nos transforma, nos hace otros. «La realidad se escapa a la mirada: / aunque me esfuerce, / siempre está incompleta», leemos en «El corazón del bosque» ${ }^{4}$. La imagen del puente se repite a lo largo de su poesía, en una reiteración que alcanza valor casi alegórico, y es, así, «la sensación de puente» que une y separa a los amantes y que ha de

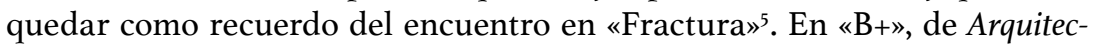

* Este trabajo se desarrolla dentro de los proyectos FFI20I6-79082-P del MINECO y EHUI4/2O de la UPV/EHU.

I Raíz, Madrid, Visor, 2008. VII Premio de Poesía Alarcos, p. 54.

2 Raíz, op. cit., p. 55.

3 La caja negra, Valencia, Pre-Textos, 2004. V Premio de Poesía Emilio Prados, p. 48.

4 Raíz, op. cit., p. Io.

5 Arquitectura yo, Madrid, Visor, 20I2. XIV Premio de Poesía Generación del 27, p. 28. 
tura yo (2012), nos ofrece otra imagen que admite una lectura metapoética: «De cerca es como el mapa de un sitio al que no has ido / pero querrías ir, / porque una aguja marca su destino concreto» ${ }^{6}$. Escribir poesía es, entonces, «tomar sin merecer»; no es un don absoluto, ni tampoco la usurpación del fuego que otorga el esfuerzo, sino el resultado de una «intuición», del «cromosoma que distingue a un poeta de alguien que sencillamente, no lo es», como escribirá en «Memorias de un lector», su poética para Deshabitados $(2008)^{8}$, y del hallazgo, del diálogo abierto con la tradición («la tradición es una jaula con las puertas abiertas» ${ }^{9}$ ), del conocimiento de la técnica y su buen uso; es una claridad medida, una luz con sentido ( $i$ Solo entonces la luz tuvo sentido?», se pregunta en «Aurora boreal, $\left.1938 »^{10}\right)$, que sugiere más que alumbra.

La escritura poética es, así, tender puentes al misterio, transitar un mapa del abismo que nos llama constantemente, como el «pájaro de hielo» que sobrevuela en "La canción del suicida $»^{\text {II }}$. Pero también es establecer un diálogo, ser en la realidad, ser circunstanciado como quería Ortega, «ser en el cuerpo de otro", compartir, convivir, coexistir, participar de lo real. No es vana la referencia a Ortega (la poesía de Josep M. Rodríguez permea conceptos filosóficos constantemente), en cuanto que el filósofo madrileño plantea una dimensión dialógica del conocimiento, en constante dinamismo, por la que la realidad es una cuestión de perspectiva, aquella que se establece en el diálogo entre un yo en constante cambio y una otredad siempre inconclusa, siempre fragmentaria: «A cada instante, / una realidad. / A cada realidad su equivalencia $»^{12}$. De ahí que el sujeto poético, ese que por cierta tendencia a generalizar se escribe en el poema como yo ( $\left(\mathrm{Yo}\right.$, o mi idea de yo $\left.»^{13}\right)$, sea el resultado de un proceso constante de construcción y de borrado, de creación y desaparición, de ser y no-ser; un yo que se eleva y se destruye en continuo diálogo entre una esencia cuestionada y una conciencia en disolución, en un tiempo y una memoria que son concebidos como fluencia, como fugacidad; un yo desenfocado para una modernidad líquida, como la definida por Zygmunt Bauman ${ }^{14}$, caracterizada por su liviandad, por su fluidez.

Toda la poesía de Josep M. Rodríguez no es sino una forma diferente

\footnotetext{
6 Arquitectura, op. cit., p. 40.

7 Ibidem.

8 En Juan Carlos Abril, Deshabitados, Granada, Diputación, col. Maillot Amarillo, 2008, p. 204.

9 Juan Carlos Abril, Deshabitados, p. 199.

Io Arquitectura yo, op. cit., p. 53.

II Arquitectura yo, op.cit., p. 54 .

I2 Raíz, op. cit., p. 29.

13 Arquitectura yo, op. cit., p. 36.

I4 Zygmunt Bauman, Modernidad líquida, México, FCE, 2007.
}

I08 
de decir yo; «llegué a la vida para decir yo», declara en «Material infancia»" (con eco de Valente). Pero «decir yo» es, para un poeta, un acto de lenguaje y un acto de existencia; un acto de habla en que nombrando lo otro pretende nombrarse a sí mismo, pero también un acto de conciencia de ser en el otro ( «ser en el cuerpo de otro», en «B+» ${ }^{16}$ ), de ser en y con lo otro, que revierte en ese yo circunstanciado. La subjetividad se construye (y se diluye), de este modo, en un acto de habla en el que se cobra conciencia de la distancia con uno mismo ( Distancia» ${ }^{17}$ ), del ser distinto en cada instante ( Cruzo una habitación y soy otra persona $\left.»^{18}\right)$, pero también de la otredad, de la necesidad de ser con los demás; entonces, «hablar de ti, / en el fondo, / también es una forma de egoísmo» («Principio y fin» ${ }^{19}$ ), y, como «Monet $»^{20}$, «Repetir un paisaje / es insistir en mí». Es el «yo biográfico» como «punto de partida de todo poeta», del que habla en "Memorias de un lector $»^{21}$, que evoca en ocasiones las voces de Jaime Gil de Biedma, Gabriel Ferrater, Robert Lowell o Sylvia Plath, entre otros; un yo que es bíos y graphos, fusión de vida y escritura (lecto-escritura), que pretende cobrar conciencia de su existencia al objetivarse en el proceso de escritura que lo devuelve a sí mismo como otro, y que traza simultáneamente su borrado, su diseminación, su disolución en ese proceso de escritura. Es La caja negra (2004) que recoge el testimonio en negativo (y la negación testimonial) de los desastres cotidianos. La escritura poética no es, entonces, el modo de plasmar la subjetividad, sino la forma de constatar su ausencia; escribir no es un modo de decirse, sino una forma de desdecirse, de negarse, de señalar un vacío, el hueco del yo; apunta a un espacio en el que el sujeto (lingüístico) tal vez estuvo, pero ya no está, y de él solo queda su diseminación. El poema construye, así, un espacio de incertidumbre, de falta de certezas, en el que nada puede afirmarse ni negarse, e incluso la propia enunciación se pone en duda, en la inestabilidad de los significados. No hay la nostalgia de una posible re-construcción utópica (tal vez sí «el negro sol de la melancolía» del que habló Nerval y sobre el que escribió Julia Kristeva), sino una presentez que se cuestiona a sí misma y que impele a la instancia receptora en su voluntad comunicativa. El yo no importa tanto, entonces, como punto de partida, sino como «el punto de llegada de todo lector» ${ }^{22}$, declarará en su poética. «Decir yo», en esas circunstancias, es un acto de habla que transforma la configuración pragmática del discurso lírico tradicional: no es decirse yo, sino decir yo a otro; apelar a la conciencia lectora

I5 Ecosistema, Valencia, Pre-Textos, 2015. Prólogo de José Andújar Almansa, p. 77.

I6 Arquitectura yo, p. 4 o.

17 Frío, Valencia, Pre-Textos, 2002, p. 3 I.

I8 Arquitectura yo, op. cit., p. 22.

I9 La caja negra, op. cit., p. 48.

20 Arquitectura yo, op. cit., p. I4.

2I En Juan Carlos Abril, Deshabitados, op. cit., p. 197.

22 Juan Carlos Abril, op. cit., p. 197. 
para borrarse en ella; preparar los dispositivos pragmáticos del poema para construirse/borrarse no en el acto de escritura, sino en el de lectura. En esa situación, solo la pluralidad tiene sentido: «cuando soy uno, no soy yo».

En ese diálogo constante en que se construye y se borra la subjetividad como alteridad, otro de los polos que entran en juego es el de la realidad cambiante, siempre distinta, siempre incompleta, siempre fluyente, inconclusa, fragmentaria: «la realidad se escapa a la mirada: / aunque me esfuerce, / siempre está incompleta $»^{23}$, «pero la realidad esconde siempre / distintas realidades $»^{24}$. «La realidad depende de uno mismo», leemos en «Monet $»^{25}$; «me transforma / la realidad», escribe en «Autorretrato $»^{26}$, contradiciendo aparentemente la afirmación anterior. Sin duda, la poesía de Josep M. Rodríguez es, en este sentido, una poesía realista, si de tal puede hablarse; una poesía que se escribe como un modo (incierto, inestable y cambiante) de ser y de estar en la realidad, como una forma de revertir lo real sobre sí mismo, consciente de que eso que llamamos «realidad» es solo una forma de nombrar lo difuso. Su realismo, que en ocasiones cobra tonos casi hiperrealistas como en los cuadros de Hopper («Silencio» $\left.{ }^{27}\right)$ o influido por el pop-art («Mitologías» $\left.{ }^{28}\right)$, es de distinto orden al tradicional. Sus poemas parten de una imagen de lo real, muchas veces de una escena cotidiana, de una «mirada» donde confluyen la intimidad proyectada del yo («todo / es una proyección $»^{29}$ ) y la perspectiva de la realidad fragmentaria, para elevarla a una categoría simbólica mediante la imagen, que no la trasciende, sino que la revierte a su origen y nos la devuelve transformada; hay una especie de mística de lo real en algunos casos, de fría pasión en una contemplación activa de la realidad que puede mostrar ecos de Antonio Gamoneda, Claudio Rodríguez o José Ángel Valente, pero también de Robert Frost o Juan Ramón Jiménez, entre otros. Pero es evidente que su poesía intenta, en muchos casos, ir más allá. En la poesía de Josep M. Rodríguez no hay atisbo de platonismo ni de idealismo filosófico; la perspectiva fragmentaria que sus poemas otorgan no evoca una totalidad ideal, un todo absoluto, sino el espacio de la incertidumbre de un tiempo abierto y una existencia difusa en un lenguaje de significados inestables. El carácter difuso de la realidad hace que las cosas posean una pluralidad semiótica («¿Por qué darle un sentido a cada cosa?», se pregunta en «Frío» $\left.{ }^{\circ}\right)$, que justificaría una concepción analógica, aquel «demonio de la analogía» de que hablaba Mallarmé. De ahí

23 Raíz, op. cit., p. Io.

24 Frío, op. cit., p. 39.

25 Arquitectura yo, op. cit., p. I4.

26 Raíz, op. cit., p. 54.

27 Raíz, op. cit., p. 18.

28 Arquitectura yo, op. cit., p. 26.

29 Arquitectura yo, op. cit., p. 22.

30 La caja negra, op. cit., p. 32 . 
algunos rasgos característicos de su escritura, como la conciencia ondulante y circular de la temporalidad, la reivindicación del instante, la concepción de la imagen como espacio de fusión entre la mirada y el pensamiento, la voluntad de sugerencia que implica al lector en la construcción de sentido, etc.

Decía Ortega, en «Verdad y perspectiva», que el filósofo es un amigo del mirar, un espectador, alguien que construye con su mirada, que dota de perspectiva a la realidad y, en consecuencia, la «realiza»; pero, como advertía Blas de Otero, «real-izándola» ${ }^{31}$. Hay toda una pedagogía de la mirada en la poesía de Josep M. Rodríguez, porque es en la mirada donde se construye la realidad en una contemplación activa, donde la realidad se eleva y revierte sobre sí misma, donde la fluidez del yo cambiante y la fluidez de lo que nombra como real se concretan en una palabra abierta a la donación de sentido por la instancia receptora. La mirada es un «salir de sí a lo otro», es el espacio de construcción y borrado de lo real, el momento del diálogo con lo otro en el instante, un ejercicio de instalarse en la fugacidad. «La mirada me explica cuanto soy», escribe en «Erosión» ${ }^{32}$; «la realidad se escapa a la mirada», leemos en «El corazón del bosque»"33. Y es que «Pensamiento y mirada se interceptan. / Dibujan una flecha, / que apunta a lo que huye», como puede leerse en «También ${ }^{34}$. Mirada y pensamiento confluyen en una poética que hace de la visualidad, de la imagen, no un mero ornamento, sino el modo de conformar la perspectiva, de dar forma al pensamiento, la manera de ahormar la materia, pues si bien «la materia / antecede a la luz, [...] es la luz / la que confiere forma» («Materia y forma $»^{35}$ ). La imagen es entonces el espacio poético por excelencia, más allá de las metáforas, porque en ella confluyen mirada y pensamiento; es, confesará el poeta, «una herramienta imprescindible [...], el corazón de mis poemas $»^{36}$. Ya señaló Octavio Paz en $E l$ arco y la lira que «sentido e imagen son la misma cosa»; y de ahí derivaría que la poesía es un «estar o ser en la realidad $»^{37}$. El poema, a través de la imagen, dice más de lo que el lenguaje codifica, lo traspasa y lo trasciende, y apunta a un más allá de las palabras; la imagen poética conforma, así, un sentido abierto a la búsqueda de interlocutor.

La confluencia de mirada y pensamiento en la imagen dota a esta de una gran potencialidad poética, que viene redoblada por la intensidad y condensación de la escritura. Josep M. Rodríguez aprendió la lección de los imagis-

3I Blas de Otero, Obra completa, Barcelona, Galaxia Gutenberg/Círculo de Lectores, 2013, p. IIO3.

32 Raíz, op. cit., p. 30.

33 Raíz, op. cit., p. Io.

34 Raíz, op. cit., p. 36.

35 La caja negra, op. cit., p. 24.

36 En Juan Carlos Abril, op. cit., p. 203.

37 Octavio Paz, El arco y la lira, México, FCE, 2004, pp. IIo y II2. 
tes anglo-americanos y del haiku japonés que tanto les influyóo ${ }^{38}$. La tendencia a la brevedad, a la eliminación de todo ornato, a la sequedad expresiva, a la desnudez poética («el haiku es un ejercicio de desnudez» $»^{39}$ ), hace que la imagen trascienda su significación más allá de su capacidad simbólica y se instaure como una entidad autónoma, superando todo fácil sentimentalismo, a la búsqueda de una emoción profunda («la emoción necesita de un proceso ${ }^{4^{0}}$ ). Apunta también a una esencialidad radical, en una poética que hace del arte de la sugerencia y del instante dos de sus pilares fundamentales. «La poesía que me interesa no alumbra, sugiere»"4, escribe en su poética. Y ese arte de la sugerencia está unido lógicamente a una poética dialógica que implica al lector en la construcción de sentido en el acto de la lectura; una "poesía abierta», apelativa, con decidida voluntad comunicativa, que completa el circuito en el acto de lectura como un acto de necesaria donación de sentido; una poesía que hace del texto un espacio de encuentro, una invitación a la construcción, una invitación a habitar el misterio de la realidad en un lenguaje desprovisto de todo adorno.

Esa tendencia a la brevedad y a la intensidad expresiva se complementa con una reivindicación del instante como núcleo temporal del poema; una tendencia a la instantaneidad, a la detención del tiempo en su propia fluencia, que revela también el haiku, y que muestra la raigambre impresionista de la poética de Josep M. Rodríguez: «Solo tengo interés por el instante», se lee en «Erosión $»^{42}$; «la vida se reinventa a cada instante», escribe en «Indecisión» ${ }^{43}$. En esa poética de «Extremos» que practica, en un proceso de integración superadora de elementos aparentemente contrarios, Rodríguez hace confluir su reivindicación de la instantaneidad, que apunta a una esencialidad difusa en la que la anécdota ha sido reducida a pura imagen significativa, con una concepción circular del tiempo y de la existencia, con un aparente elemento panenteísta ( todo es parte de todo» ${ }^{44}$, «todo se recicla»45), en la que todo acto revierte sobre su origen («me regreso al origen $»^{46}$ ), aunque este sea incierto, y todo ser se integra en una existencia superior, en una esencia presentida, aunque oscura. El árbol, entonces, anticipa el bosque («el árbol que no es bosque / lo anticipa» ${ }^{47}$ ); la «Astilla» aguarda «para cerrar

38 Vid. Hana o la flor del cerezo, Valencia, Pre-Textos, 2007. V Premio Internacional del Crítica Amado Alonso.

39 En Juan Carlos Abril, op. cit., p. 201.

40 Juan Carlos Abril, op. cit., p. 198.

4I Juan Carlos Abril, op. cit., p. 202.

42 Raíz, op. cit., p. 30.

43 Raíz, op. cit., p. $5 \mathrm{I}$.

44 Frío, op.cit., p. 4I.

45 Arquitectura yo, op. cit., p. 28.

46 Ecosistema, op. cit., p. 63.

47 Arquitectura yo, op. cit., p. 9. 
el ciclo» ${ }^{48}$ que le dio origen; la madera del árbol anuncia el ataúd; los círculos de los troncos revelan la circularidad del tiempo, esa «Continuidad» ${ }^{49}$ de las cosas. No hay contradicción entre instantaneidad y continuidad, pues el tiempo se detiene en su propia fluencia, como el dolor ( $\mathrm{Ola}$ de frío» ${ }^{\circ}$ ). No hay tampoco en estos poemas un canto elegíaco, a pesar de que se afirme

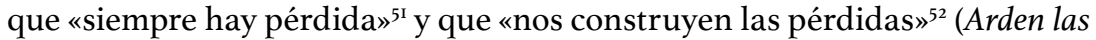
pérdidas, escribiría Gamoneda), porque el tiempo no se detiene, «no cicatriza [...] tras nosotros», ni «cicatriza [...] frente a mí», pues «la memoria es un pozo sin final» («Asfalto (versión segunda)»" no muere, / se transforma» ${ }^{54} \mathrm{y}$ «lo que nos duele / no es lo que perdemos, / sino lo que renace»"5; por eso, afirma en otro poema, «me he negado a la elegía ${ }^{56} \mathrm{y}$ "canto lo que se pierde / porque me asusta aquello que he ganado» «iHasta dónde nos llevan los recuerdos?» ${ }^{58}$, se pregunta en un momento; hasta allí donde renace la memoria, donde el tiempo nunca se ha detenido y fluye constantemente; un tiempo sin origen ni fin que adquiere cierta apariencia mitológica pero que ostenta una marcada conciencia histórica. El tiempo es pura fluencia, mera ondulación, como señaló Deleuze, y vivir la vida es expandirse en «círculos crecientes / que nazcan y se extiendan desde mí» ${ }^{59}$; por eso el retorno a la memoria no otorga la felicidad de la derrota que tiene la elegía, porque el dolor sigue fluyendo en el pasado, y el tiempo no cicatriza. La memoria no es estática, sino que, como esa imagen que se repite en diversos poemas, es como un arroyo helado en cuyo interior «se ha quedado atrapada una hoja de roble» ${ }^{60}$; los recuerdos «fluyen / lentos / como un arroyo helado» ${ }^{61}$. El panta rei heraclitiano adquiere, así, una nueva formulación en la poesía de Josep M. Rodríguez, porque también la memoria fluye, ondula en su propio pasado, revierte sin alcanzar sus orígenes.

Decía Heidegger que «la belleza es uno de los modos de presentarse la verdad como desocultamiento» y que «el poema es el relato del desocultamiento de lo ente» ${ }^{62}$. El poema consigue, consecuentemente, llevar a lo

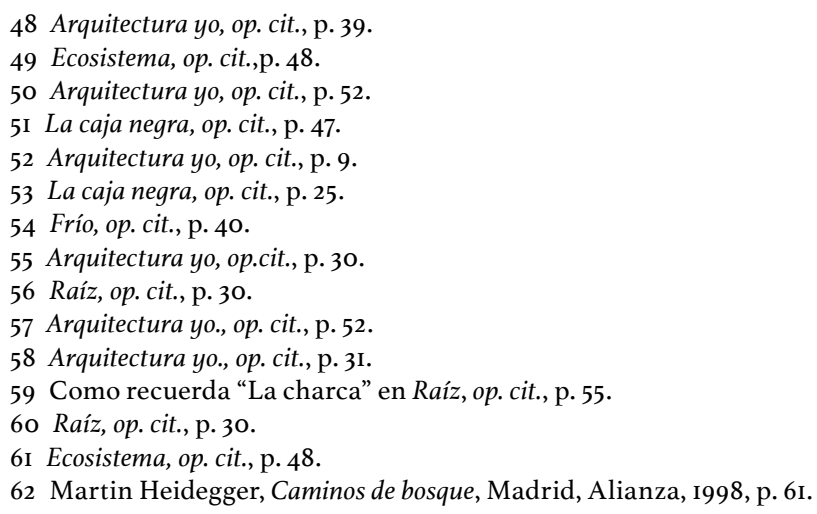


abierto al ser en tanto ser, consigue desocultar el ser en su propia esencia, mostrarlo en su ocultación esencial; desocultarlo en su misterio y no desvelarlo. Ya Heráclito señalaba que «a la naturaleza le place ocultarse» ${ }^{63}$. A algo semejante apunta Josep M. Rodríguez al referirse a la labor escultórica de Pablo Gargallo (y podría haber referido quizás también la de Jorge de Oteiza o Eduardo Chillida). La labor del poeta, como la del escultor, no es tanto la de construir la materia, sino la de hacer su vaciado; proceder por elipsis, por eliminación; construir el hueco, la ausencia; habitar el misterio que no se desvela, mostrar al ser en su propia ocultación, en la «oscuridad de la que procedemos». No hay en su escritura, por lo tanto, una construcción, sino un borrado constante, una «erosión», una diseminación, una construcción negativa, destructiva, que acaba mostrando la ausencia. En poesía, no importa tanto lo que se dice como lo que se calla («Lo que se dice en un poema tiene tanto valor como lo que no se dice» ${ }^{64}$, declarará en su poética); el silencio es parte sustancial de lo dicho, es el espacio en que se manifiesta lo indecible, aquello que no puede ser dicho sino cuando el lenguaje calla. «La poesía se vuelve contra sí», afirmaba Yves Bonnefoy ${ }^{65}$. Y es que, en poesía el lenguaje se desdice, se niega en su propia enunciación, no afirma sino la incertidumbre; el acto de habla ni afirma ninguna certeza ni niega nada, no constata sino su propia carencia; no es un acto de imposición, sino una invitación a la libertad. Allí donde se habla en estos poemas no hay ni una voluntad de poder, ni una conciencia de ser, ni un sujeto que se dice; sino que este a lo sumo se manifiesta como voluntad comunicativa, como apelación sin origen a un lector. El poema interpreta la realidad, más que la representa; la mirada fragmentaria del poeta vislumbra las pistas de aquello que oculta una realidad más amplia y que solo puede mostrarse en el lenguaje como ausencia, como carencia. Pero no nos engañemos, porque no hay en estos poemas una aspiración a una ontología totalitaria, sino una concepción fragmentaria de la escritura, donde el vaciado representa la ausencia, el hueco, la incompletud de lo real. No hay, pues, a pesar de ciertos ecos, una aspiración mística a una totalidad inalcanzable, sino una invitación a la comprensión, a la participación, que muestra el mundo y el texto poético, en su fragmentariedad, como proceso y no como resultado; una invitación a participar en la construcción de lo que solo por pereza intelectual seguimos llamando realidad.

63 Heráclito, Fragmentos, Buenos Aires, Aguilar, 1977, fragmento DK 22, B I23.

64 En Juan Carlos Abril, op. cit., p. 202.

65 Vid. Pierre Garrigues, Poétiques du fragment, París, Klincksieck, 1995, p. 39. 